\title{
A High-gain and Low-scattering Waveguide Slot Antenna of Artificial Magnetic Conductor Octagonal Ring Arrangement
}

\author{
Xiao LIU, Jun GAO, Xiangyu CAO, Yi ZHAO, Wenqiang LI, Sijia LI, Nan LI \\ Information and Navigation College, Air Force Engineering University, Fenghao Road 1st Xi'an 710077, China \\ 382500638@qq.com,gjgj9694@163.com, xiangyucaokdy@163.com,519763316@qq.com, lfjwymlwq@126.com, \\ 1sj051@126.com,2449545348@qq.com \\ Manuscript received July 2, 2015
}

\begin{abstract}
A novel design of high-gain and low-scattering waveguide slot antenna is proposed in this paper. Firstly the scattering pattern of artificial magnetic conductor (AMC) composite surface is estimated by array factor analysis method. The comparison between octagonal ring arrangement and chessboard arrangement proves that the former arrangement has the characteristic of diffuseness-like and expands the bandwidth of radar cross section (RCS) reduction. Secondly, the metal surface of waveguide slot antenna (WSA) is replaced by the octagonal ring arrangement composite surface (ORACS). The gain is improved because of spurious radiation units which are around the slot. At the same time using the phase cancellation principle, a backscatter null achieves RCS reduction in the vertical direction. Experimental results show that for the novel antenna after loading with the ORACS, the gain is improved by $5 \mathrm{~dB}$; the bandwidth of RCS reduction (reduction greater than $10 \mathrm{~dB}$ ) is 5.24-5.92 GHz.
\end{abstract}

\section{Keywords}

Waveguide slot antenna, artificial magnetic conductor, octagonal ring arrangement

\section{Introduction}

With rapid development of stealth technology, RCS has become a major specification of aircrafts. Antenna which is an indispensable part of the wireless communication system is also the main contributor of the total RCS of the aircraft. It has practical significance to reduce the RCS of the aircraft and improve the radiation performance of the antennas.

In 1999, D. Sievenpiper proposed a new 2-D metamaterial, Artificial Magnetic Conductor [1], [2]. When plane wave arrives on the structure, the phase of reflect wave keeps unchanged within a particular frequency band. In [3], [4], AMC is used as the back-cavity or cladding to achieve the low-profile antennas. In order to improve the gain of antenna, AMC is loaded on the aperture, [5-8]. In
[5], the AMC is loaded around the rectangular microstrip antenna, the gain is improved in consequence of the change of surface current. In [9], an ultra-thin absorber is manufactured by loading with lump resistance. In [10], the metal surface of WSA is replaced by the ultra-thin absorber, and the gain is decreased in consequence of loading with the lump resistance.

In 2007, Paquay proposed a novel structure which is combined of AMC and PEC by chessboard arrangement [12]. Using the phase cancelation principle, the RCS is reduced in specified space. Even without the loss component, through arranging properly, the purpose of gain enhancement and RCS reduction is achieved. In [13], the composite surface is used where AMC and PEC are arranged by square ring and the WSA are integrated. The gain is improved by $1.7 \mathrm{~dB}$, and the fractional bandwidth of RCS reduction (reduction greater than $10 \mathrm{~dB}$ ) is $8.5 \%$. In [14], the composite surface which is combined of AMC and PEC by chessboard arrangement is loaded on the WSA, the gain is improved by $5.1 \mathrm{~dB}$, and the fractional bandwidth is $5.8 \%$. In [15], the fractional bandwidth of RCS reduction gets extended by changing the cell, but the gain is improved limitedly by $3 \mathrm{~dB}$.

In this paper, a high-gain low-scattering waveguide slot antenna of AMC octagonal ring arrangement is optimized and simulated. Experiments are carried out to verify the simulation results, and the experimental results show that the gain of the antenna is improved by $5 \mathrm{~dB}$, and the fractional bandwidth of RCS reduction is $12.3 \%$.

\section{Analysis of ORACS}

ORACS is a composite surface which is combined $\mathrm{PEC}$ and $\mathrm{AMC}$ by octagonal ring arrangement. Compared with chessboard arrangement, more backscatter beams are achieved due to the irregular arrangement.

As the plane wave arrives on the surface, the amplitude of the surface current is equal while the phase is inverse; the scattering field is described as: 


$$
\begin{aligned}
& E_{\mathrm{PEC}}=A \cdot \exp \left(j \theta_{1}\right) \cdot S_{\mathrm{PEC}}, \\
& E_{\mathrm{AMC}}=A \cdot \exp \left(j \theta_{2}\right) \cdot S_{\mathrm{AMC}} .
\end{aligned}
$$

The total scattering field is described as:

$$
E=E_{P E C} \cdot A 1+E_{A M C} \cdot A 2
$$

in which $S$ represents areas of the AMC and PEC, $\theta_{1} \approx 180^{\circ}$, $\theta_{2} \approx 0^{\circ}, A 1$ and $A 2$ are the parameters of the array.

An AMC cell is designed as ' 0 ' element with a 0deg phase response, and PEC is designed as ' 1 ' element with a 180deg phase response. The composite surfaces are shown in Fig. 1. Elements are regarded as single cells in

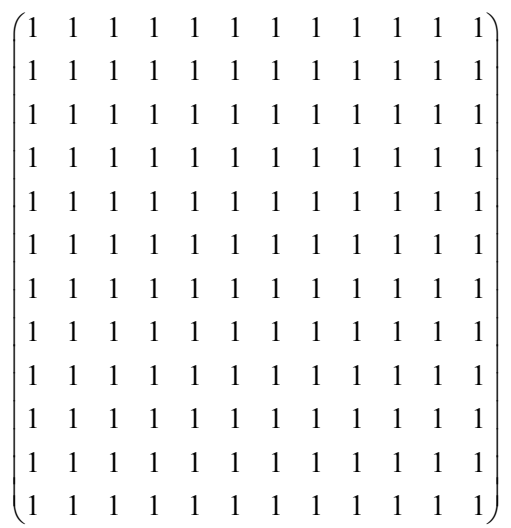

(a)



(b)

$\left(\begin{array}{llllllllllll}0 & 0 & 0 & 1 & 1 & 1 & 1 & 1 & 1 & 0 & 0 & 0 \\ 0 & 0 & 1 & 1 & 1 & 1 & 1 & 1 & 1 & 1 & 0 & 0 \\ 0 & 1 & 1 & 0 & 0 & 0 & 0 & 0 & 0 & 1 & 1 & 0 \\ 1 & 1 & 0 & 0 & 0 & 0 & 0 & 0 & 0 & 0 & 1 & 1 \\ 1 & 1 & 0 & 0 & 0 & 0 & 0 & 0 & 0 & 0 & 1 & 1 \\ 1 & 1 & 0 & 0 & 1 & 1 & 1 & 1 & 0 & 0 & 1 & 1 \\ 1 & 1 & 0 & 0 & 1 & 1 & 1 & 1 & 0 & 0 & 1 & 1 \\ 1 & 1 & 0 & 0 & 0 & 0 & 0 & 0 & 0 & 0 & 1 & 1 \\ 1 & 1 & 0 & 0 & 0 & 0 & 0 & 0 & 0 & 0 & 1 & 1 \\ 0 & 1 & 1 & 0 & 0 & 0 & 0 & 0 & 0 & 1 & 1 & 0 \\ 0 & 0 & 1 & 1 & 1 & 1 & 1 & 1 & 1 & 1 & 0 & 0 \\ 0 & 0 & 0 & 1 & 1 & 1 & 1 & 1 & 1 & 0 & 0 & 0\end{array}\right)$

(c)

Fig. 1. Diagram of composite structure reflection phase. (a) PEC, (b) Chessboard arrangement, (c) Octagonal ring arrangement.



(a)



(b)



(c)

Fig. 2. Three-dimensional scattering array factor. (a) PEC, (b) Chessboard arrangement, (c) Octagonal ring arrangement.

an antenna array, the amplitude is 1 , and the distance between the cells is $0.15 \lambda$. The reflection phase information and cell location information are translated into antenna array information. The scattering patterns of three composite surfaces are analyzed by using the method of array factor [16], shown as Fig. 2.

Shown as Fig. 2, the reflect energy of octagonal ring arrangement is scattered into more space than the chessboard arrangement, and the characteristic of diffuseness-like is proved.

In order to illustrate the characteristic of extending the band of RCS reduction, the method of array factor analysis is taken again. The amplitude of RCS reduction is observed by picking up the value of array factor in $+z$ axis. When the 
' 0 ' element is designed as an AMC cell with a 30deg phase response, ' 1 ' keeps unchanged in Fig. 1, 144, 8, 1.68 represent the value of PEC, chessboard arrangement and octagonal ring arrangement respectively. When the ' 0 ' element is designed as an AMC cell with a -30deg phase response, ' 1 ' keeps unchanged, 144, 16, 12.38 represent the value of PEC, chessboard arrangement and octagonal ring arrangement respectively. The value of array factor in the $+z$ axis of different arrangement is shown in Fig. 3. By comparison the value of three arrangements, it is obvious that the octagonal ring arrangement is significantly less than chessboard arrangement and PEC in the same frequency band, that is, the bandwidth of RCS reduction is expanded.



Fig. 3. Value of array factor in $+z$ axis of different arrangement.



(a)

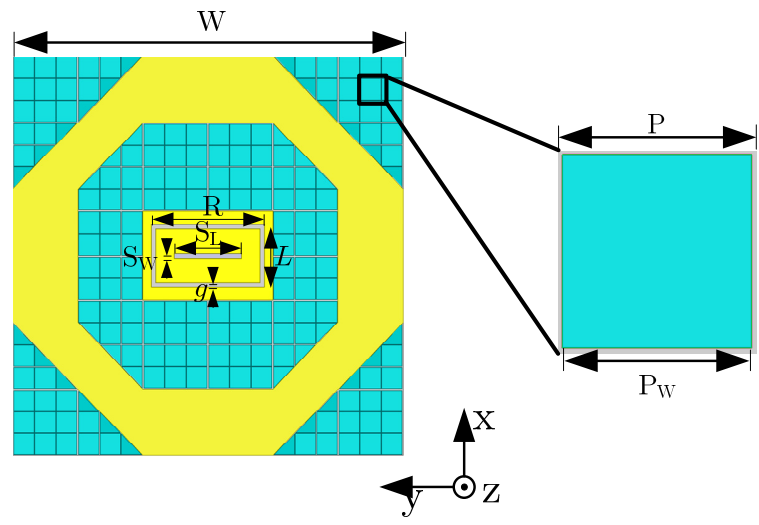

(b)



$\bar{y}$

\section{Simulation of the WSA Loading with ORACS}

Figure 4 gives the scheme of WSA loading with ORACS. The metal surface is replaced by ORACS, which become a part of aperture, and the metal ground keeps un-changed. The sizes after optimizing are: $W=150 \mathrm{~mm}$, $h=3 \mathrm{~mm}, R=42 \mathrm{~mm}, L=22 \mathrm{~mm}, g=1 \mathrm{~mm}, S_{\mathrm{L}}=26 \mathrm{~mm}$, $S_{\mathrm{W}}=2 \mathrm{~mm}, P=8.2 \mathrm{~mm}, P_{\mathrm{w}}=7.9 \mathrm{~mm}$.

\subsection{Analysis of Scattering Characteristic of ORACS}

The different loading methods and the RCS reduction curves of WSA are reported in Fig. 5 and Fig. 6. Shown as Fig. 6, the results prove that both the arrangements work well to reduce RCS. The RCS reduction bandwidth of loading $\mathrm{B}$ is narrower than loading $\mathrm{C}$, and $\mathrm{RCS}$ reduction value of loading $\mathrm{C}$ is significantly less than loading $\mathrm{B}$.

Figure 7 shows the scattering pattern of loading $C$, the energy is diffused into much space, which agrees with the former prediction of the array factor method.

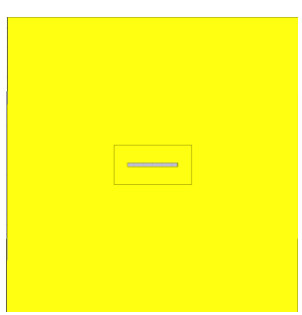

(a)



(b)



(c)

Fig. 5. ORACS of three loading methods. (a)Loading A, (b) Loading B, (c) Loading C.



Fig. 6. Simulation of RCS reduction curve under normal incident wave.

Fig. 4. WSA loading with ORACS. (a) Overall, (b) ORACS and single unit. 




Fig. 7. Loading C's three-dimensional scattering pattern under normal incident wave.

\subsection{Analysis of Radiation Performance of WSA Loading with ORACS}

Figure 8 and 9 show the $S_{11}$ curves and the radiation patterns of WSA loading with different ORACS. The performance of $\mathrm{S}_{11}$ keeps unchanged after loading with the ORACS. The beam width of loading B is wider than the original antenna, and the gain is decreased. The gain of loading $\mathrm{C}$ is improved, and the beam width is narrowed. The maximum gain and the resonant frequency are given in Tab. 1.

\begin{tabular}{|c|c|c|c|}
\hline Loading & A & B & C \\
\hline Resonant frequency $(\mathrm{GHz})$ & 5.66 & 5.66 & 5.66 \\
\hline Gain $(\mathrm{dB})$ & 7.38 & 6.99 & 13.11 \\
\hline
\end{tabular}

Tab. 1. The maximum gain and the resonant frequency.



Fig. 8. The reflection coefficient of the three loading methods.



(a) E-plane



(b) H-plane

Fig. 9. The pattern of the three loading methods at the resonant frequency.

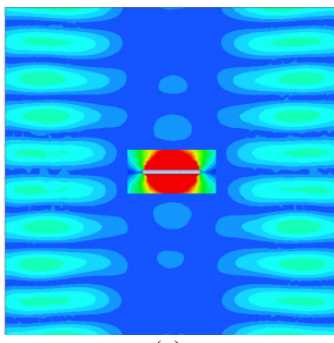

(a)



(c)

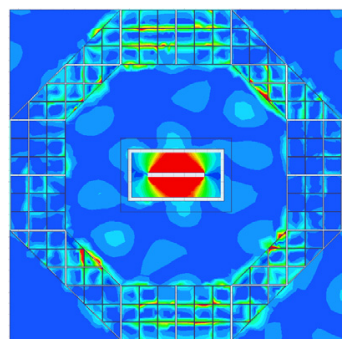

(b)



$0.0000++600$
Fig. 10. Surface E-field distribution of the three loading methods at $5.66 \mathrm{GHz}$ in same scale (0-1500 V-per-meter). (a) loading A, (b) loading B, (c) loading $\mathrm{C}$.

Figure 10 shows the surface current distribution of three loading methods. For loading B, the gain is decreased because the AMC cells are far from the slot, and spurious radiation units are not excited effectively. For loading $\mathrm{C}$, the AMC cells are around the slot, and the spurious radiation units which are excited strongly form an array with the slot, and the gain gets improved greatly.

\section{Fabrication and Measurement}

To verify the simulation results, the WSA of loading $\mathrm{C}$ is illustrated in Fig. 11 and has been experimentally studied. The proposed ORACS was fabricated using an optical lithographic process on a 3-mm-thick F4B-2 substrate with $\varepsilon_{\mathrm{r}}=2.65$ and fixed on the WSA by four screws.

The $\mathrm{S}_{11}$ curve was measured using Agilent N5230C vector network analyzer, shown in Fig. 12. Comparing to the curve of the reference antenna (Loading A), the curve of the improved antenna (Loading C) is almost the same. The resonant frequency of the reference antenna and the 
improved antenna are both at $5.66 \mathrm{GHz}$ and the bandwidths are $5.48-5.84 \mathrm{G} \mathrm{Hz}$ and $5.5 \mathrm{GHz}-5.84 \mathrm{GHz}$, respectively.



Fig. 11. Antenna sample.



Fig. 12. The measured reflection coefficient curve.


(b) Radiation pattern.

Fig. 13. Measurement setup.



(a) E-plane



(b) H-plane

Fig. 14. The measured radiation pattern at the resonant frequency.



Fig.15. Measured RCS reduction curve.

The experimental environment is shown in Fig. 13. The radiation pattern is measured in a microwave anechoic chamber and depicted in Fig. 14. The distance between the measured antenna and the horn antenna is $2.3 \mathrm{~m}(\geq 10 \lambda)$, satisfying the far field requirement. The measured results show that gain is enhanced by $5 \mathrm{~dB}$ in both E-plane and H-plane for the reference antenna.

The result of measured RCS reduction curve is shown in Fig. 15. The RCS reduction peak is $16.62 \mathrm{~dB}$ at 5.64 GHz. $10 \mathrm{~dB}$ reflection reduction is achieved from $5.24 \mathrm{GHz}$ to $5.92 \mathrm{GHz}$ which correspond to a fractional value of $12.3 \%$. Considering fabrication and measurement tolerance, the measured results show accordance with the simulated ones. 
These measurements above validate that our proposed design shows excellent performance in the two aspects of radiation and scattering.

In Tab. 2, the radiation and scattering performance of four kinds of WSA loading with composite surface are summarized.

\begin{tabular}{|c|c|c|c|c|}
\hline & {$[13]$} & {$[14]$} & {$[15]$} & $\begin{array}{c}\text { This } \\
\text { paper }\end{array}$ \\
\hline $\begin{array}{c}\text { Resonant frequency } \\
(\mathrm{GHz})\end{array}$ & 7.0 & 5.7 & 5.66 & 5.66 \\
\hline $\begin{array}{c}\text { Size of the aperture } \\
(\mathrm{mm})\end{array}$ & $\begin{array}{c}70 \\
(1.5 \lambda)\end{array}$ & $\begin{array}{c}126 \\
(2.39 \lambda)\end{array}$ & $\begin{array}{c}120 \\
(2.26 \lambda)\end{array}$ & $\begin{array}{c}150 \\
(2.83 \lambda)\end{array}$ \\
\hline $\begin{array}{c}\text { Gain enhancement } \\
(\mathrm{dBi})\end{array}$ & 1.7 & 5.1 & 3.2 & 5 \\
\hline $\begin{array}{c}\text { The fractional bandwidth } \\
\text { of RCS reduction } \\
(\geq 10 \mathrm{~dB}),(\%)\end{array}$ & 8.5 & 5.8 & 20.0 & 12.3 \\
\hline
\end{tabular}

Tab. 2. Comparison of design performance of WSA loading with different $\mathrm{AMC}$ composite surfaces.

\section{Conclusion}

In this paper, ORACS is loaded on the WSA to enhance gain and achieve the low-scattering characteristic. Simulated S-parameters, radiation patterns, gain, directivity, and RCS reduction of the WSA are compared with the measured results. Measured results indicate that the RCS of the WSA has been dramatically reduced and the gain enhancement is $5 \mathrm{~dB}$. Experimentally and theoretically, it can be observed that the proposed WSA has the advantages of the gain-enhancement and RCS reduction.

\section{Acknowledgments}

Authors thank the supports from the National Natural Science Foundation of China under Grant (No.61271100, No.61471389, and No.61501494). They also thank the reviewers for their valuable comments.

\section{References}

[1] SIEVENPIPER, D., ZHANG, R.F., BROAS, R.F.J., et al. High-impedance electromagnetic surfaces with forbidden bands at radio and microwave frequencies. IEEE Transactions on Microwave Theory and Techniques, 1999, vol. 47, no. 11, p. 2059-2084. DOI: $10.1109 / 22.798001$

[2] YANG, F., AMINIAN, A., RAHMAT-SAMII, Y. A novel surface-wave antenna design using a thin periodically loaded ground plane. Microwave and Optical Technology Letters, 2005, vol. 47, no. 3. p. 240-245. DOI: 10.1002/mop. 21136

[3] FOROOZESH, A., SHAFAI, L. Effects of artificial magnetic conductors in the design of low-profile high-gain planar antennas with high-permittivity dielectric superstrate. IEEE Antennas and Wireless Propagation Letters, 2009, vol. 7, no. 8 p. 10-13. DOI: 10.1109/LAWP.2008.916684

[4] TURPIN, J. P., WU, Q., WERNER, D. H., et al. Near-zero-index metamaterial lens combined with AMC metasurface for high-directivity low-profile antennas. IEEE Transactions on
Antennas and Propagation. 2014, vol. 62, no. 4, p. 1928-1936. DOI: 10.1109/TAP.2014.2302845

[5] FERESIDIS, A.P., GOUSSETIS, G., WANG, S. H., et al. Artificial magnetic conductor surfaces and their application to low-profile high-gain planar antennas. IEEE Transactions on Antennas and Propagation, 2005, vol. 53, no. 1, p. 209-215. DOI: 10.1109/TAP.2004.840528

[6] YANG, W. C., WANG, H., CHE, W. Q., et al. A wideband and high-gain edge-fed patch antenna and array using artificial magnetic conductor structures. IEEE Antennas and Wireless Propagation Letters, 2013, vol. 55, no. 12, p. 769-772. DOI: 10.1109/LAWP.2013.2270943

[7] PRAKASH, P., ABEGAONKAR, M. P. A., BASU, A., et al. Gain enhancement of a CPW-fed monopole antenna using polarization-insensitive AMC structure. IEEE Antennas and Wireless Propagation Letters, 2013, vol. 55, no. 12, p. 1315-1318. DOI: $10.1109 /$ LAWP.2013.2285121

[8] FOROOZESH, A., SHAFAI, L. Investigation into the application of artificial magnetic conductors to bandwidth broadening, gain enhancement and beam shaping of low profile and conventional monopole antennas. IEEE Transactions on Antennas and Propagation, 2011, vol. 59, no. 1, p. 4-20. DOI: 10.1109/TAP.2010.2090458

[9] GAO, Q., YIN, Y., YAN, D. B., et al. Application of metamaterials to ultra-thin radar-absorbing material design. Electronics Letters, 2005, vol. 41, no. 17 p. 936-937. DOI: 10.1049/el:20051239

[10] LIU TAO, CAO XIANG-YU, GAO JUN, et al. Design of metamaterial absorber and its applications for waveguide slot antenna. Acta Physica Sinica, 2012, vol. 61, no. 18, p. 128-135. (In Chinese) DOI: 10.7498/aps.61.184101

[11] YANG, H. H., CAO, X. Y., GAO, J., et al. An ultra-thin metamaterial absorber and its application in reducing res of slot antenna. Journal of Electronics and Information Technology, 2012, vol. 34, no. 11, p. 2790-2794. DOI: 10.3724/SP.J.1146.2012.00676

[12] PAQUAY, M., IRIARTE, J. C., EDERRA, I., et al. Thin AMC structure for radar cross-section reduction. IEEE Transactions on Antennas and Propagation, 2007, vol. 55, no. 12, p. 3630-3638. DOI: 10.1109/TAP.2007.910306

[13] TAN, Y., YUAN, N. C., YANG, N., et al. Improved RCS and efficient wave guide slot antenna. Electronics Letters, 2011, vol. 47 , no. 10 , p. $582-583$. DOI: $10.1049 /$ el.2011.0842

[14] YAO, X., CAO, X. Y., GAO, J., et al. Low scattering waveguide slot antenna design with gain enhancement. Chinese Journal of Radio Science, 2012, vol. 27, no. 6, p. 1141-1145. ISSN: 1005-0388

[15] ZHAO YI, CAO XIANG-YU, ZHANG DI, et al. Design of high-gain broadband low-RCS waveguide slot antenna. Acta Physica Sinica, 2014, vol. 63, no. 3, p. 108-115. (In Chinese) DOI 10.7498/aps.63.034101

[16] LI WEN-QUIANG, GAO JUN, CAO XIANG-YU, et al. A kind of shared aperture radar absorbing material with absorber and phase cancellation characteristics. Acta Physica Sinica, 2014, vol. 63 , no. 12 , p. 157-164. (In Chinese) DOI: 10.7498/aps.63.124101

\section{About the Authors ...}

Xiao LIU was born in Jinzhong, Shanxi province, in 1992. $\mathrm{He}$ received the B. S. degree from the Information and Navigation College, Air Force Engineering University in 2014. He is now a graduate student. His research interest is in electromagnetic metamaterial. He has been working with 
the Military Communication and Navigation Antenna and EMC Lab, since 2014. His research activity has been focused in the broadband and fractal artificial magnetic conductor, coding metamaterial and its application for RCS reduction of antennas. He is awarded the 2014 Third Prize of the National Graduate Mathematical Modeling Contest.

Jun GAO received the B.Sc and M.A.Sc degrees from the Air Force Missile Institute in 1984 and 1987, respectively. He joined the Air Force Missile Institute in 1987 as an assistant teacher. He became an associate professor in 2000. He is currently a professor of the Information and Navigation College, Air Force Engineering University of CPLA. He has authored and coauthored more than 100 technical journal articles and conference papers, and holds one China soft patent. His research interests include smart antennas, electromagnetic metamaterials and their antenna applications.

Xiangyu CAO received the B.Sc and M.A.Sc degrees from the Air Force Missile Institute in 1986 and 1989, respectively. She joined the Air Force Missile Institute in 1989 as an assistant teacher. She became an associate professor in 1996. She received Ph.D. degree in the Missile Institute of Air Force Engineering University in 1999. From 1999 to 2002, she was engaged in postdoctoral research in Xidian University, China. She was a Senior Research Associate in the Dept. of Electronic Engineering, City University of Hong Kong from June 2002 to Dec 2003. She is currently a professor of the Information and Navigation College of the Air Force Engineering University of CPLA. She is the IEEE senior member from 2008. She has authored and coauthored more than 200 technical journal articles and conference papers, and holds one China soft patent. She is the coauthor of two books entitled, Electromagnetic Field and Electromagnetic Wave, and Microwave Technology and Antenna published in 2007 and 2008, respectively. Her research interests include smart antennas, electromagnetic metamaterials and their antenna applications, and electromagnetic compatibility. She is a reviewer of Applied Physics Letter, Journal of Applied Physics, IEEE Transactions on Antennas \& Propagation, and IEEE Antennas Wireless Propagation Letter.

Yi ZHAO received the B.S. and M.S. degree from the Information and Navigation Institute, Air Force Engineering University of CPLA, China, in 2011 and 2013, respectively. Currently, he is working toward Ph.D degree at the School of Information and Navigation, Air Force Engineering University. His research interest is in electromagnetic metamaterials and their antenna applications. He has authored and coauthored more than 10 technical journal articles and conference papers.

Wenqiang LI received the B.Eng. and M Eng. degree from the Air Force Engineering University, Xi' an China, in 2009 and 2011, respectively. His research interests lay in the areas of artificial electromagnetic metamaterial, especially the left handed metamaterial from September 2009 to December 2011. He is currently working toward Ph.D degree at the Information and Navigation Institute of the Air Force Engineering University. His main interests include metamaterial design and the RCS reduction of antennas.

Sijia LI has received the B. Eng. degree in Electronics and Information Engineering from Guangxi University, Nanning, China, in 2009 and the M. Eng. degree in Information and Telecommunication Engineering from the Air Force Engineering University, Xi'an China, in 2011. He is currently working toward Ph.D degree in Electronic Science and Technology (Electronic Field and Microwave Technology) at the Information and Navigation Institute of Air Force Engineering University. His research activity has been focused in the broadband perfect metamaterial absorber and its application for RCS reduction of antennas. He has authored and coauthored more than 40 scientific papers in major journals and international conferences.

Nan LI was born in Xianyang, Shaanxi province, in 1992. She received the B. S. degree from the Lanzhou Jiaotong University in 2014. She is now a graduate student. Her research interest is in signal processing. 